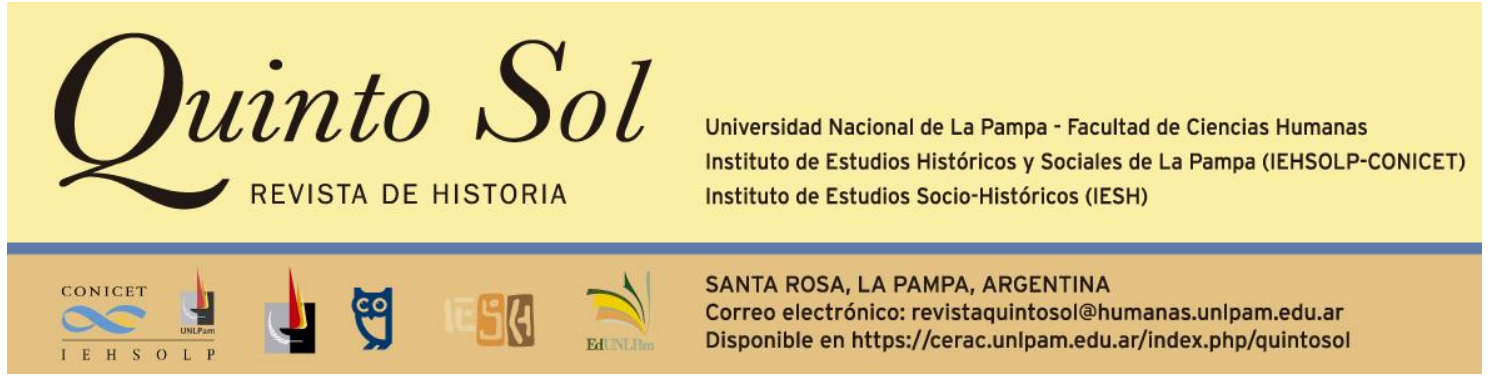

Quinto Sol, vol. 23, n² 2, mayo-agosto 2019, ISSN 1851-2879, pp. 1-4

DOI: http://dx.doi.org/10.19137/qs.v23i2.3623

Esta obra se publica bajo licencia Creative Commons 4.0 Internacional. (Atribución-No ComercialCompartir Igual)

\title{
María Florencia Osuna. La intervención social del Estado. El Ministerio de Bienestar Social entre dos dictaduras (Argentina, 1966-1983). Rosario: Prohistoria, 2017, 261 páginas.
}

\author{
Valeria Natividad Almirón \\ Consejo Nacional de Investigaciones Científicas y Técnicas \\ Universidad Nacional de Lanús. Instituto de Salud Colectiva \\ Argentina \\ Correo electrónico: vnalmiron@gmail.com
}

Reconstruir la historia reciente no supone una tarea sencilla cuando se pretende investigar desde nuevos enfoques el Estado y las políticas públicas en Argentina. No obstante, la historiadora María Florencia Osuna asume el desafío en el libro que es la adaptación de su tesis doctoral y se denomina "La intervención social del Estado. El Ministerio de Bienestar Social entre dos dictaduras (Argentina, 1966-1983)". En este estudio indaga las políticas, actores y proyectos institucionales de la cartera que inauguró el gobierno de facto de Juan Carlos Onganía (1966-1969) como parte de la reestructuración de Ministerios.

La propuesta innovadora de Osuna no desconoce los enfoques clásicos que se asentaron en las características represivas y autoritarias del período (Cavarozzi, 1997; Rouquié, 1998; De Riz, 2007; O’Donnell, 2009), en cambio, los recupera en tanto entiende ese contexto caracterizado por la cohesión que no sería posible sin la construcción del consenso en la población mediante las políticas sociales que desarrollaron estos gobiernos. En este sentido, su libro forma parte de las nuevas pesquisas que buscan analizar las intervenciones y el ideario de los funcionarios, como 
el caso de Laura Rodríguez (2013) que investiga el diseño e implementación de políticas públicas en la Secretaría de Educación, Gabriela Gómez (2011) trabaja ejes similares para la Secretaría de Estado de Promoción y Asistencia a la Comunidad (SEPAC) y la Secretaría de Vivienda (2017). Asimismo, Guido Giorgi (2010; 2015), Guido Giorgi y Fortunato Mallimaci (2012) analizan a los funcionarios católicos de ideas comunitaristas que formaron parte del gobierno de Onganía.

El libro se estructura en siete capítulos que se agrupan en tres partes. En ellas, podemos hallar ideas/conceptos claves que marcaron la impronta de la época en materia de proyecto institucional. La primera sección, recupera las intervenciones del Ministerio de Bienestar Social (MBS) durante la "Revolución Argentina" (1966-1973) y el interés depositado en el concepto de "comunidad"; la segunda parte examina a la cartera durante el tercer gobierno peronista (1973-1976) donde el foco se situó en la imagen de la "emergencia" y finalmente en el último momento, durante el Proceso de Reorganización Nacional (PRN) (1976-1983), se atendió a la concepción de "familia". Así, las ideas de comunidad, emergencia y familia construyeron al sujeto social que necesitó ser asistido al momento que crearon las agencias estatales que urgían para su atención.

En la primera parte, Osuna analiza cómo el concepto de comunidad acaparó el pensamiento de los funcionarios del MBS durante la "Revolución Argentina". Su definición se asoció a las comunidades "naturales" y en cierta medida "medievales", que definían al sujeto social: el ciudadano, la profesión, los integrantes de la familia (padre, madre, hijo...) y se alejó de las categorías del lugar en la producción (asalariado/proletario) en tanto involucraban al mundo del trabajo. En diálogo con esa concepción se creó la SEPAC, encargada de llevar adelante ese ideario. Ahora bien, la noción de comunidad fue parte de los lineamientos de instituciones internacionales como la Doctrina de Seguridad Nacional que abogaba por el desarrollo y la seguridad en los países de la periferia. Pues bien, la primera paradoja que aparece es que el concepto del período, comunidad, encierra un modo de organización anticuado, pero, al mismo tiempo, en sintonía con los criterios de organismos extranjeros.

Además, como identifica la autora, la idea del desarrollo de la comunidad se ajustaba a las nociones de la iglesia católica difundidas en las redes civiles del laicado de la cual participaban los funcionarios de Bienestar Social. Aunque, junto con esta expresión de la derecha católica, se encontraba el proyecto de los técnicos de la derecha liberal que desde su espacio en el Ministerio de Economía presionaban por introducir su visión respecto al rumbo que debía asumir el gobierno de facto. En este sentido, Osuna enriquece el enfoque de la(s) derecha(s) en general y en Argentina en particular, que lejos de ser grupos homogéneos y monolíticos, disputan los rumbos de la política nacional.

En la segunda sección, la autora indaga el MBS durante el tercer gobierno de Juan Domingo Perón (1971-1974) y de María Estela Martínez de Perón (1974-1976), quien asumió tras la muerte de su esposo como parte de la fórmula electoral que la tuvo como vicepresidenta. En ese período, el concepto de emergencia orientó el "quehacer" de las políticas sociales y se creó la Dirección Nacional de Emergencias Sociales (DINES), encargada de intervenir ante el llamado de una urgencia. La cobertura espacial de dicha dependencia incluía todo el territorio nacional mediante el transporte aéreo y terrestre tanto de víveres como de personas. Osuna, repara que en la DINES, dentro del repertorio de lo que se entendía como "emergencias sociales", se 
encontraban intervenciones disimiles, que incluían tanto la asistencia como la coacción. En este sentido, por ejemplo, la Dirección podía acudir al llamado de un vecino que denunciaba disturbios y hacerse presente para ejercer la represión, como también asistir con alimentos a los damnificados por una catástrofe natural.

En la tercera y última parte, la historiadora examina la actuación de la cartera de Bienestar Social durante el PRN (1976-1983). En este período, se asumió desde las políticas sociales que se debía intervenir sobre la familia en general $y$, en particular, sobre los niños, jóvenes y ancianos/jubilados. El diagnóstico era que la familia estaba en "peligro" y se había producido una "brecha generacional", fruto de los cambios culturales y poblacionales que distanciaban a los integrantes más grandes de la familia respecto a los más pequeños. Pues bien, se debía favorecer el encuentro entre ellos, desarrollando un vínculo ameno para que los ancianos transmitieran buenas enseñanzas a los más pequeños. La autora afirma, que en función de proteger a los jubilados y a los niños, a los primeros se les aumentó los haberes y a los segundos se los incentivó a participar en actividades educativas con fuerte impronta "militarista".

Los jóvenes, por otra parte, debían ser atendidos por los adultos para que no fuesen coaccionados por el "enemigo subversivo", porque creían que los invitaba a corromperse física y moralmente a través del consumo de drogas, la promiscuidad y la homosexualidad. En respuesta a esa evaluación, se creó el Cuerpo de Vigilancia Juvenil (CVJ), encargado de reprimir y detener a jóvenes en la vía pública. Entonces, las políticas hacia la juventud se complementaban entre prácticas legales, la vigilancia del CVJ en las calles, e ilegales a través del secuestro y la desaparición de personas.

A nuestro entender, la obra logra mostrar en profundidad la intervención social del período 1966-1983, sin perder de vista las características represivas y autoritarias. Ahora bien, nos parece que el libro también podría organizarse desde las trayectorias de tres jefes de la cartera de Bienestar Social: Francisco Manrique, José López Rega y Santiago de Estrada. Cada uno de ellos, con su ideario respecto a las políticas públicas en los tres momentos en que se divide el libro (1966-1973, 1973-1976, 1976-1983), son el rostro humano del Estado (Bohoslavsky y Soprano, 2010) y una forma de reinterpretar el período, como dice Osuna, entre el "garrote y la zanahoria".

\section{Referencias bibliográficas}

1. Bohoslavsky, E. y Soprano, G. (Eds.) (2010). Un Estado con rostro humano. Funcionarios e instituciones estatales en Argentina (desde 1880 a la actualidad). Buenos Aires, Argentina: Prometeo.

2. Cavarozzi, M. (1997). Autoritarismo y democracia (1955-1966). La transición del Estado al mercado en la Argentina. Buenos Aires, Argentina: Ariel.

3. De Riz, L. (2007). La política en suspenso 1966/1976. Buenos Aires, Argentina: Paidós.

4. Giorgi, G. (2010). Redes católicas y Estado en la "Revolución Argentina". Ciencias Sociales/Ciências sociais y religiâo, 12, 53-78.

5. Giorgi, G. (2015). En los pliegues de la planificación del onganiato: el comunitarismo como política estatal (1966-1970). Anuario IEHS, 29-30, 159-175. Recuperado de http://anuarioiehs.unicen.edu.ar/2015-14.html

6. Giorgi, G. y Mallimaci, F. (2012). Catolicismo, nacionalismo y comunitarismo en política social. Redes católicas en la creación del Ministerio de Bienestar Social 
de Argentina (1966-1970). Revista Cultural y Religión, 6 (1), 113-144.

Recuperado

http://www.revistaculturayreligion.cl/index.php/culturayreligion/article/view/51/ 60

7. Gómez, G. (2011). El Onganiato y los sectores populares: funcionarios, ideas y políticas de la secretaría de Estado de Promoción y Asistencia a la Comunidad (1966-1970). Anuario del Centro de Estudios Históricos "Prof. Carlos S. A. Segriti", 11, 279-302. Recuperado de https://cehsegreti.org.ar/archivos/FILE_00000388_1412624516.pdf

8. Gómez, G. (2017). "Baires 2000". Imaginarios y visiones de futuro en las agencias de Planeamiento y Desarrollo de las dictaduras militares de Argentina (19661983). Estudios Sociales del Estado, 3 (6), 66-93. Recuperado de http://www.estudiossocialesdelestado.org/index.php/ese/article/view/124

9. O’Donnell, G. (2009). El Estado burocrático autoritario 1966-1973. Triunfos, derrotas y crisis. Buenos Aires, Argentina: Prometeo.

10. Rodríguez, L. (2013). Los católicos desarrollistas en Argentina. Educación y planeamiento en los años 1960. Diálogos (Maringá, Online), 17 (1), pp. 155-184. DOI: $10.4025 /$ dialogos.v17i1.723

11. Rouquié, A. (1998). Poder militar y sociedad política en la Argentina. Tomo II 1943/1973. Buenos Aires, Argentina: Emecé. 